\title{
Long-Lived Concentric Eyewalls in Typhoon Soulik (2013)
}

\author{
YI-TING YANG \\ Office of Disaster Management, New Taipei City, Taiwan \\ ERIC A. HENDRICKS \\ Marine Meteorology Division, Naval Research Laboratory, Monterey, California \\ HUNG-CHI KuO \\ Department of Atmospheric Sciences, National Taiwan University, Taipei, Taiwan \\ MeLinda S. PENG \\ Marine Meteorology Division, Naval Research Laboratory, Monterey, California
}

(Manuscript received 24 March 2014, in final form 25 May 2014)

\begin{abstract}
The authors report on western North Pacific Typhoon Soulik (2013), which had two anomalously long-lived concentric eyewall (CE) episodes, as identified from microwave satellite data, radar data, and total precipitable water data. The first period was $25 \mathrm{~h}$ long and occurred while Soulik was at category 4 intensity. The second period was $34 \mathrm{~h}$ long and occurred when Soulik was at category 2 intensity. A large moat and outer eyewall width were present in both CE periods, and there was a significant contraction of the inner eyewall radius from the first period to the second period. The typhoon intensity decrease was partially due to encountering unfavorable environmental conditions of low ocean heat content and dry air, even though inner eyewall contraction would generally support intensification. The $T$-Vmax diagram (where $T$ is the brightness temperature and Vmax is the best track-estimated intensity) is used to analyze the time sequence of the intensity and convective activity. The convective activity (and thus the integrated kinetic energy) increased during the CE periods despite the weakening of intensity.
\end{abstract}

\section{Introduction}

One scenario of tropical cyclone (TC) rapid intensity change is associated with the concentric eyewall (CE) formation and the subsequent eyewall replacement cycle (ERC). The ERC is defined as the time period from the formation of the secondary eyewall, to its contraction, and finally to the replacement of the original decaying inner eyewall. The ERC process that leads to weakening is well known and discussed in Willoughby et al. (1982) and Black and Willoughby (1992). They showed that Hurricanes Anita, David, and Andrew formed CE structures,

Corresponding author address: Hung-Chi Kuo, Department of Atmospheric Sciences, National Taiwan University, No. 1, Sec. 4, Roosevelt Road, Taipei 10617, Taiwan.

E-mail: kuo@as.ntu.edu.tw and documented the ERC occurrence and subsequent weakening using aircraft observations.

The ERC time scale in numerical models such as Terwey and Montgomery (2008), Qiu et al. (2010), Zhou and Wang (2009), and Ortt and Chen (2008) are in the range of $6-18 \mathrm{~h}$. The radar observations of Typhoon Lekima (Kuo et al. 2004) and the aircraft observation of Hurricane Andrew (1992) (Willoughby and Black 1996) both indicated that the ERC time is approximately $6 \mathrm{~h}$. Sitkowski et al. (2011) used aircraft data to analyzed 24 ERC events and compared with microwave satellite data. They found that the average ERC event as identified by aircraft data lasts $36 \mathrm{~h}$, which is much longer than that of the microwave satellite data: $17.5 \mathrm{~h}$.

Using aircraft reconnaissance flight level data, Maclay et al. (2008) showed that while the intensity weakens during the ERC, the integrated kinetic energy and the TC size increases. Their results suggested that secondary 


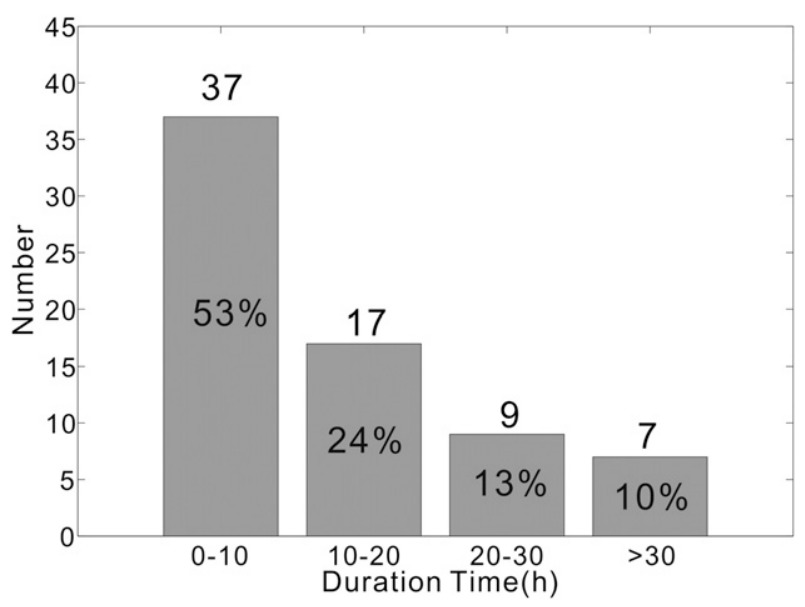

FIG. 1. The number of concentric eyewall (CE) cases as a function of duration time in the western North Pacific basin between 1997 and 2011. The data are from Yang et al. (2013).

eyewall formation and the ERC are dominated by internal dynamical processes. Sitkowski et al. (2011) also suggested the ERC process might lead to increases in both storm size and integrated kinetic energy. Furthermore, the ERC time requirement, intensity change, and radii change have large variances due to the intensity and structural changes.

Yang et al. (2013) studied the structural and intensity changes of CE typhoons in the western North Pacific using microwave satellite images between 1997 and 2011. Using an original objective method based on the microwave imagery, they identified three different $\mathrm{CE}$ types: $\mathrm{CE}$ with an eyewall replacement cycle (ERC; 53\%), CE with no replacement cycle (NRC; $24 \%$ ), and CE that is maintained for an extent period (CEM; 23\%). The inner (outer) eyewall dissipates in the ERC (NRC) type in less than $20 \mathrm{~h}$ after CE formation in microwave satellite data. The CEM type maintains its CE structure for more than $20 \mathrm{~h}$ (31-h mean).

We analyze the CE duration time ${ }^{1}$ of $70 \mathrm{CE}$ cases from Yang et al. (2013) data in Fig. 1. The average CE duration time for all case is $16 \mathrm{~h}$ with 13 -h standard deviation. There are only seven cases $(10 \%)$ in which the CE structure is maintained longer than $30 \mathrm{~h}$. These cases have very large moats $(67.5-\mathrm{km}$ mean) and outer eyewall widths (70-km mean), as seen from microwave satellite data. Of the cases mentioned, there are multiple CE formations in Typhoon Winnie (1997) and Typhoon

\footnotetext{
${ }^{1}$ The $\mathrm{CE}$ duration time is the time period during which the CE structure is maintained as identified by the objective method from microwave satellite data. We do not use the ERC time (i.e., the formation to the demise of $\mathrm{CE}$ structure in microwave data) to avoid the problem of inadequate temporal resolution.
}

Chaba (2004). Typhoon Winnie (1997) is the largest typhoon in the western North Pacific with large eyewalls for a long time (Zhang et al. 2005). The large size of moat and outer eyewall width are important characters of the CEM cases as well as the multiple CE formation TCs (Yang et al. 2013). It is possible that the large moat size may delay the ERC and affect TC intensity change (Kuo et al. 2009).

In this paper, we report on such a unique case: western North Pacific Typhoon Soulik (2013), which had two very long-lived $\mathrm{CE}$ structures. We use microwave satellite image, radar image, and total precipitable water (TPW) images to investigate the CE structural and intensity change of Typhoon Soulik.

\section{Data and methods}

Microwave satellite images are used to examine the CE characteristics of Typhoon Soulik between 9 and 12 July 2013. In particular, we use the passive Special Sensor Microwave Imager (SSM/I) 85-GHz, Special Sensor Microwave Imager/Sounder (SSMIS) 91-GHz horizontal polarized orbital imagery, passive Tropical Rainfall Measuring Mission (TRMM) Microwave Imager (TMI) data (Kummerow et al. 1998), and the Advanced Microwave Scanning Radiometer 2 (AMSR-2) 89-GHz imagery. These data were obtained from the Naval Research Laboratory (NRL) Marine Meteorology Division in Monterey, California (Hawkins et al. 2001, 2006). The NRL microwave satellite images are reprocessed using the antenna gain function associated with the sampled radiometer data to create high-resolution $(1-2 \mathrm{~km})$ products that can aid in defining inner-storm structural details (Hawkins and Helveston 2004, 2008). We also use the Central Weather Bureau (CWB) radar, the Japan Meteorological Agency (JMA) Miyako radar, and the total precipitable water (TPW) image in the study.

The Morphed Integrated Microwave Imagery-Total Precipitable Water (MIMIC-TPW) presents TPW over the ocean based on an algorithm developed by Alishouse et al. (1990), which derives these values from a linear function of 19-, 22- and 37-GHz blackbody brightness temperature $T_{B}$ available from SSM/I microwave sensors. The final product is an hourly composite of many swaths of TPW retrievals, advanced to the required time using1000-, 850-, and 700-hPa wind from the Global Forecast System (GFS) model (Wimmers and Velden 2011).

We use the objective method to identify CE characteristics from microwave satellite image (Yang et al. 2013). We examined 28 microwave satellite images between 9 and 12 July by the objective method. Out of these, $11 \mathrm{CE}$ images were identified, including two $\mathrm{CE}$ 
TABLE 1. Five criteria (Yang et al. 2013) for CE, QCE, and No-CE cases: circles and crisscrosses represent the cases that satisfy the criterion; and the circles with a slash indicate the cases that satisfy the relaxed criterion. The $T_{\mathrm{Binner} \_\min }, T_{\mathrm{Bmax}}$, and $T_{\mathrm{Bouter} \_ \text {min }}$ represent the minima $T_{B}$ near inner core, local maxima $T_{B}$ between inner and outer $T_{B}$, and the minima $T_{B}$ near outer eyewall from inner core along each radial profiles. The $\sigma_{\text {inner_min }}\left(\sigma_{\text {outer_min }}\right)$ represent the standard deviation of the minima $T_{B}$ near inner core (near outer eyewall) calculated by each radial profile. The $T_{B}$ is the brightness temperature calculated by objective method from microwave satellite image (Yang et al. 2013).

\begin{tabular}{|c|c|c|c|}
\hline & $\mathrm{CE}$ & QCE & No-CE \\
\hline $\begin{array}{l}\text { Criterion 1: Possible moat located } \\
\quad \text { Min }-\max -\min \text { in } T_{B} \\
\left(T_{\text {Binner_min }}-T_{\text {Bmax }}-T_{\text {Bouter_min }}\right)\end{array}$ & $\bigcirc$ & O & O \\
\hline $\begin{array}{l}\text { Criterion 2: Significant moat } \\
\quad T_{\text {Bmax }} \geqq \sigma_{\text {outer_min }}+T_{\text {Bouter_min }} \\
T_{\text {Bmax }} \geqq \sigma_{\text {inner_min }}+T_{\text {Binner_min }}\end{array}$ & 0 & O & $\times$ \\
\hline $\begin{array}{l}\text { Criterion 3: Strong outer convection } \\
T_{\text {Bouter_min }} \leqq 230 \mathrm{~K}\end{array}$ & O & $\left(T_{\text {Bouter_min }} \leqq 240 \mathrm{~K}\right)$ & $\times$ \\
\hline $\begin{array}{l}\text { Criterion } 4 \text { : Symmetric structure } \\
\geqq 5 / 8 \text { sectors }\end{array}$ & O & $\begin{array}{c}\theta \\
(\geqq 4 / 8 \text { sectors })\end{array}$ & $\times$ \\
\hline $\begin{array}{l}\text { Criterion 5: Not a spiral outer band } \\
\text { The difference of two outer eyewalls } \leqq 50 \mathrm{~km}\end{array}$ & ○ & 0 & $\times$ \\
\hline
\end{tabular}

formations. If we relax the criteria by making the outer eyewall convection criterion $10 \mathrm{~K}$ weaker (from 230 to $240 \mathrm{~K}$ ) than that of Yang et al. (2013) and using one-half symmetry to identify the CE structure, $19 \mathrm{CE}$ images were identified (Table 1). These eight additional CE images, which satisfy the relaxed criteria, are called quasi-CE (QCE) images. Table 1 shows the five criteria for CE, QCE, and No-CE images in our analysis period. The inner eyewall radius $r_{0}$, moat width $d_{0}$, and outer eyewall width $w_{0}$ of CE are calculated by the objective method (Yang et al. 2013).

\section{Observation and analysis}

Typhoon Soulik was category 1 on the Saffir-Simpson hurricane scale on 9 July (Fig. 2). It rapidly strengthened in the next $24 \mathrm{~h}$ and was at category 4 intensity on 10 July when it moved westward in the southern periphery of subtropical high pressure system. Then, it weakened and became a category 1 typhoon before made landfall on Taiwan (between 1800 UTC 12 July and 0000 UTC 13 July). Following the methods of Qiu (1999), the sea surface height anomaly (SSHA) features observed from satellite altimetry in Fig. 2a show Soulik encountered a pre-existing cold eddy. Moreover, the TPW shown in Fig. $2 b$ indicated that midlevel dry air entrained into Soulik from the northwest. These unfavorable environmental conditions coincided with the weakening of Soulik before landfall as reported by the Joint Typhoon Warning Center.

During Typhoon Soulik's lifetime, two CE structures are identified. The first CE period (hereafter period I) is between 0729 UTC 9 July and 0832 UTC 10 July (Fig. 3a, $25 \mathrm{~h}$ long), and the second period (hereafter period II) is between 0630 UTC 11 July and 1649 UTC 12 July (Fig. 3b, $34 \mathrm{~h}$ long). We use the relaxed criteria for CE recognition in the period I. An apparent CE structure also could be found between 0500 UTC 9 July and 1500 UTC 10 July ( $34 \mathrm{~h}$ ) by the TPW image. The outer eyewall of Soulik was less symmetric and weaker in convection in period I, possibly due to an intrusion of midlevel dry air from the north into the western part of the storm (Fig. 3a). In period II, the CE structure also could be found by JMA and CWB radar when it approached Miyako and Taiwan, and the midlevel dry air intrusion was not as pronounced (Fig. 3b). The large

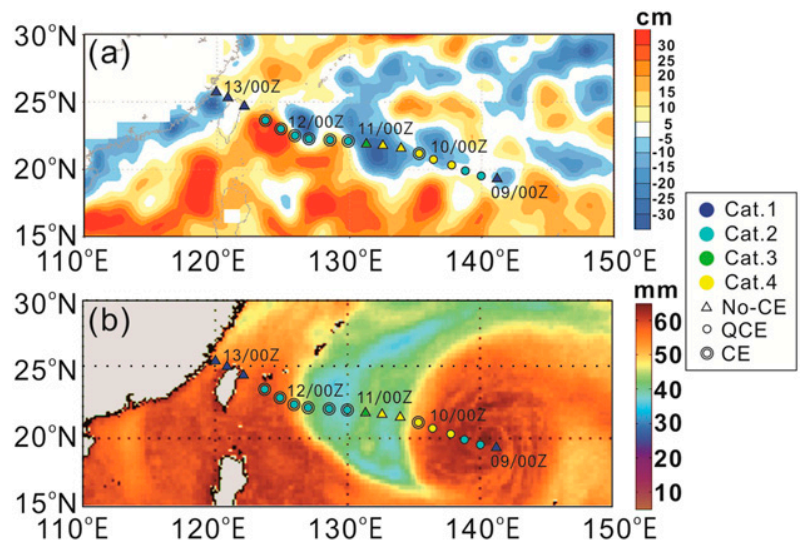

FIG. 2. (a) Typhoon Soulik's track and the sea surface height anomaly (SSHA) on 8 Jul 2013. The positive and negative SSHA indicate warm and cold eddy over ocean. (b) Typhoon Soulik's track and total precipitable water on 9 Jul 2013. The colors of markers indicate typhoon's intensity. The dark blue, light blue, green, and yellow represent the category 1,2,3, and 4 intensity of TC, respectively. The triangle, circle, and concentric circle indicate No-CE, quasi CE (QCE), and CE, respectively. 


\section{(a) \\ Period I}

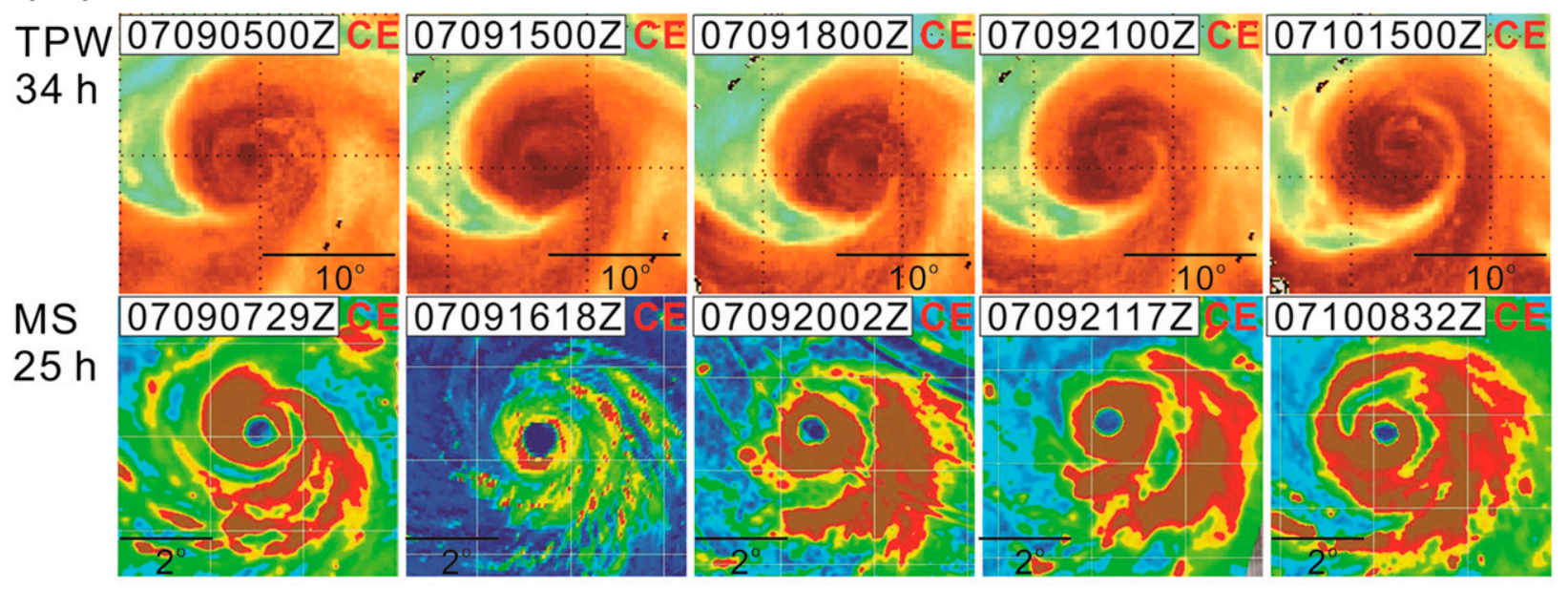

(b)

Period II

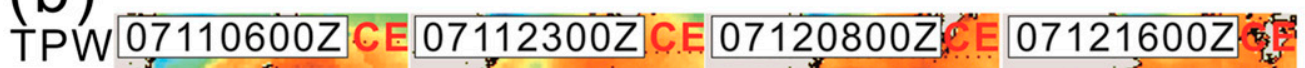

$34 \mathrm{~h}$
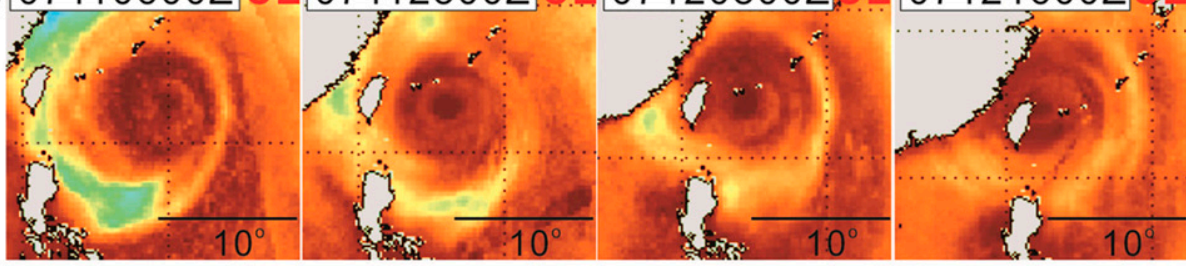

MS

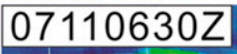

$34 \mathrm{~h}$
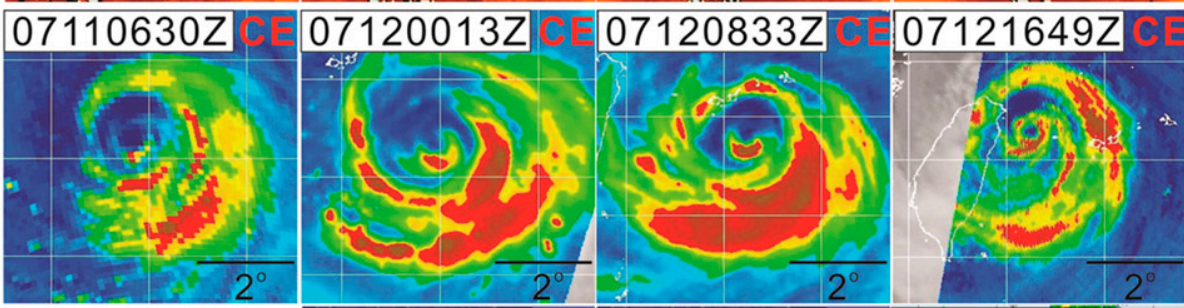

Radar

$18 \mathrm{~h}$

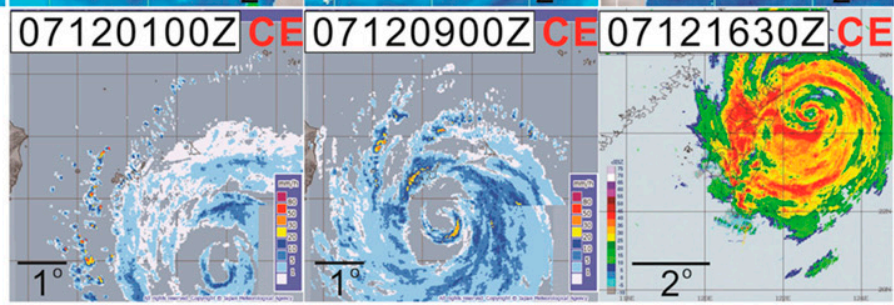

FIG. 3. The image sequences of total precipitable water (TPW), microwave satellite (MS), and radar in the (a) period I (from 0500 UTC 9 Jul to 1500 UTC 9 Jul) and (b) period II (from 0600 UTC 11 Jul to 1600 UTC 12 Jul). The observed duration times were also shown. The length scale is shown in each panel.

moats and outer eyewall sizes of the last $18 \mathrm{~h}$ in period II is also confirmed with the radar image. Furthermore, the CE structure can be clearly seen in the TPW image between 0600 UTC 11 July and 1600 UTC 12 July. Typhoon Soulik maintained the CE structure for $34 \mathrm{~h}$ according to sequences of microwave satellite image and TPW in Fig. 3b. This 34-h period of CE duration time is longer than the mean duration time $(31 \mathrm{~h})$ of CEM cases in Yang et al. (2013). In summary, Soulik had two CE structures during its lifetime and maintained the CE structures for at least 25 and $34 \mathrm{~h}$, respectively.

Yang et al. (2013) found the CEM cases are typically at relatively high intensity, and have large moat and outer eyewall widths that last for a long period of time. They speculated that the outer eyewall of the CEM type can end up taking a much longer time to contract because of 


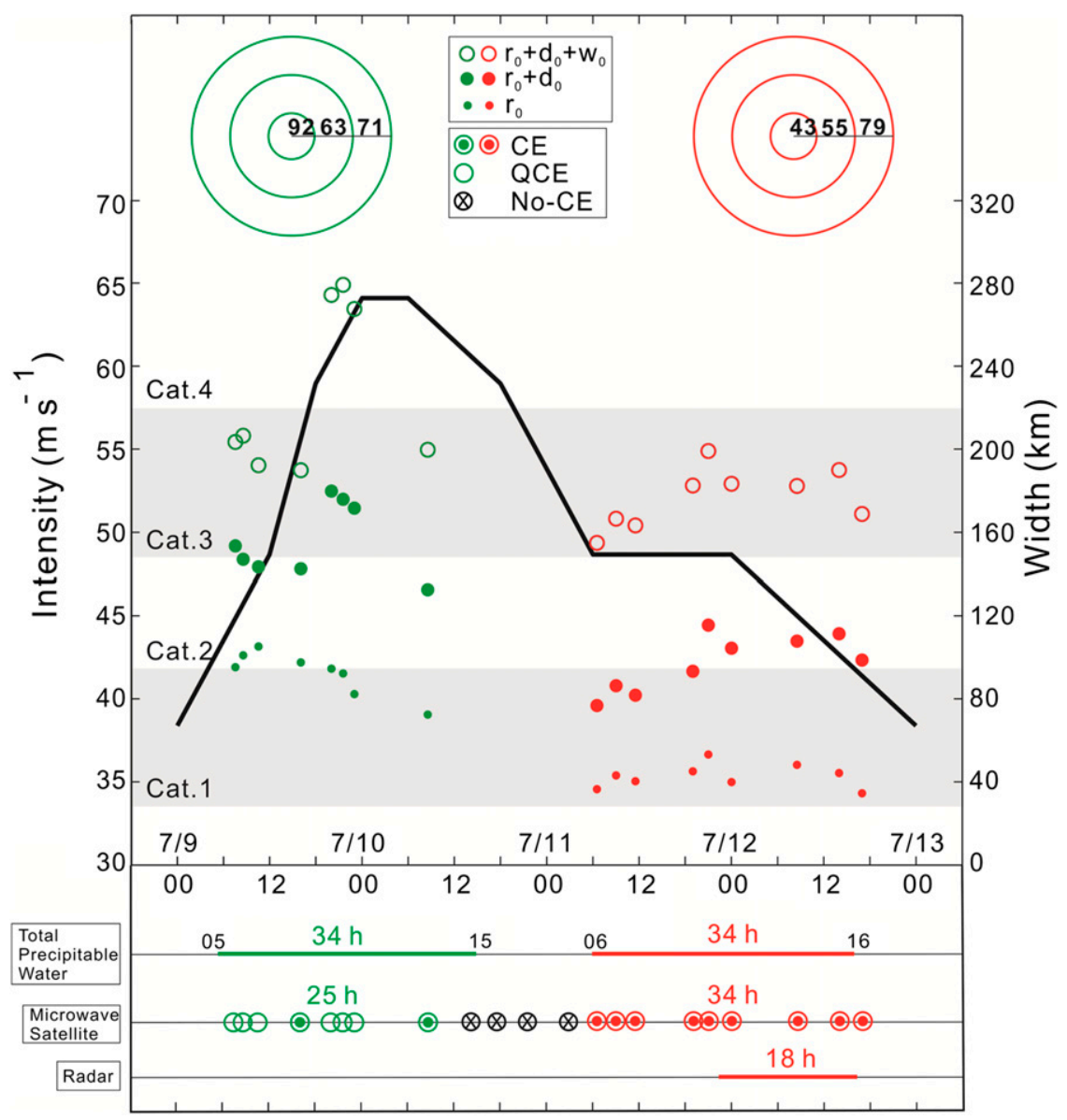

FIG. 4. Typhoon Soulik's intensity and the time of CE periods determined by total precipitable water image, microwave satellite image, and radar image. (bottom) Circles with a dot, circles, and circles with a crisscross indicate $\mathrm{CE}$ image, $\mathrm{CE}$ image determined by relaxed criteria (QCE), and No-CE image, respectively. (middle) Small dots, large dots, and circles represent $r_{0}, r_{0}+d_{0}$, and $r_{0}+d_{0}+w_{0}$, respectively (where $r_{0}$ is the inner eyewall radius, $d_{0}$ is the moat width, and $w_{0}$ is the outer eyewall width). The green color indicates period I (from 0500 UTC 9 Jul to 1500 UTC 9 Jul) and red color indicates period II (from 0600 UTC 11 Jul to 1600 UTC $12 \mathrm{Jul}$ ). The black line represents intensity. (top) The mean $r_{0}, d_{0}$, and $w_{0}$ of Typhoon Soulik in the period I (green) and II (red). (Unit: km.)

its larger scale, or the large moat and outer eyewall width reduce the barotropic instabilities of CEM storms, helping maintain the $\mathrm{CE}$ structures for a long time. It is also possible the large moat size reduces the interference between the convection/subsidence couplet of the inner and outer eyewalls. We find that Typhoon Soulik had a large moat width $d_{0}$ and outer eyewall width $w_{0}$ in both periods (Fig. 4). This is consistent with the characteristic of the CEM typhoons. The most significant change is the inner eyewall radius $r_{0}$ in the two CE periods, as the inner radius at period $\mathrm{I}$ is twice as large as at period II. The decrease of inner radius, however, is accompanied by the intensity weakening. Although eyewall contraction is generally associated with intensification, the environmental factors of dry air and low ocean heat content may have been more significant in this case. In addition, the standard deviations of $r_{0}, d_{0}$, and $w_{0}$ in period $\mathrm{I}(10.5,20.3$, and $23.4 \mathrm{~km}$, respectively) are larger than that of the period II $(5.8,11.1$, and $5.4 \mathrm{~km}$, respectively). This is due to the fact that both QCE and CE structures occurred in period I while period II only had distinct CE structure. The size of the CE structure is very stable during period II while Soulik was at category-2 intensity.

Typhoon Soulik had only a significant inner eyewall radius reduction from period I to period II and the moat and the outer eyewall width are of similar size. In contrast to Typhoon Soulik, Typhoon Winnie (1997) had two $\mathrm{CE}$ periods with duration times of 20 and $46.5 \mathrm{~h}$, respectively. The $46.5 \mathrm{~h}$ is the longest CE duration record in the western North Pacific. The $r_{0}, d_{0}$, and $w_{0}$ of Typhoon 
Winnie (1997), as determined from the satellite data were 17 (55) km, 57 (137) km, and 40 (137) $\mathrm{km}$ in the first (second) period. Typhoon Chaba (2004) is another case with long-lived multiple CE formation. It also had two CE periods, which are 24 and $35.5 \mathrm{~h}$, respectively. The $r_{0}, d_{0}$, and $w_{0}$ were $27.1(50) \mathrm{km}, 44.3(70) \mathrm{km}$, and 24.2 (85) $\mathrm{km}$ in the first (second) period. Both typhoons have significant expansion of all three size parameters from the first to the second period. Sitkowski et al. (2011) indicated that multiple ERC processes is a primary mechanism for both the integrated kinetic energy and the TC size to increase. It is possible that the expansion of storm size not observed in Typhoon Soulik is due to the lack of complete ERC. It appears that the dynamics have yet to be understood for this kind of phenomena of $\mathrm{CE}$ with multiple long duration time.

The intensity and convective activity (CA) changes can be demonstrated by the $T$-Vmax diagram (Yang et al. 2013); a diagram in which the ordinate is convective activity in terms of the brightness temperature $T$ in contrast to the background averaged in the $400 \mathrm{~km}$ by $400 \mathrm{~km}$ area of satellite imagery centered at the eye, and the abscissa is Vmax, which is the best track-estimated intensity. The background is calculated as the highest $5 \%$ of brightness temperature in the $400 \mathrm{~km}$ by $400 \mathrm{~km}$ area. The size of the area is chosen because the averaged CE diameter size in the western North Pacific is approximately $300 \mathrm{~km}$ (Yang et al. 2013). Moreover, the diameter of the Typhoon Soulik is close to $400 \mathrm{~km}$ (Fig. 4). Typhoon Soulik's $T$-Vmax diagram shows that CA increases twice in its lifetime (Fig. 5). Both the CA and the storm intensity of Soulik first increased during period I, and maintained the CA and storm intensity for approximately $11 \mathrm{~h}$. While the CA and the storm intensity slightly decreased in the 6-h time period after period I, the CA increased when the storm intensity decreased before period II. Then the CA increased and the intensity was maintained for approximately $18 \mathrm{~h}$ during period II. In general, the CA is maintained or increased during the two CE periods in Typhoon Soulik while the storm intensity weakened. Consistent with Yang et al. (2013), the CA increase in Soulik is mainly due to the increase of the deep convection. This may lead to an increase in the stormintegrated kinetic energy.

\section{Conclusions}

We have documented the fundamental characteristics of the long-lived multiple CE phenomena, using a case study of Typhoon Soulik (2013). Typhoon Soulik had two long-lived CE periods of 25 and $34 \mathrm{~h}$, respectively, as documented by microwave and TPW imagery. We have shown a mechanism for storm structural change and

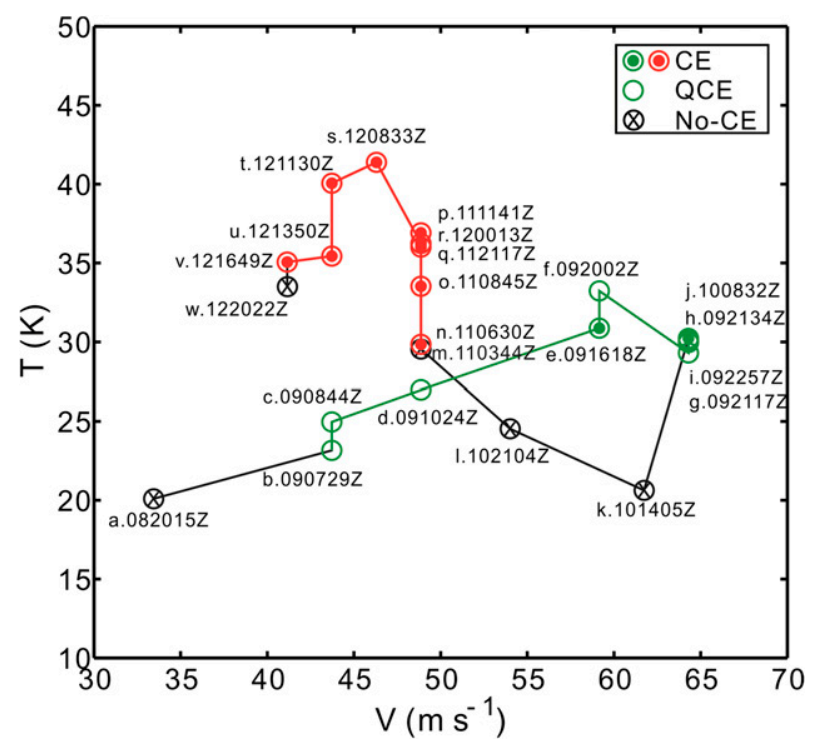

FIG. 5. $T$-Vmax diagrams for Typhoon Soulik (2013); $T$ is the difference between the background $T_{B}$ and averaged $T_{B}$ for each image within $400 \mathrm{~km}$ by $400 \mathrm{~km}$ centered at the storm. The green color indicates period I (from 0500 UTC 9 Jul to 1500 UTC 9 Jul) and the red color indicates period II (from 0600 UTC 11 Jul to 1600 UTC $12 \mathrm{Jul}$ ). Circles with a dot indicate CE image, circles indicate CE image determined by relax criteria (QCE), and circles with a crisscross indicate No-CE image.

growth associated with these long-lived CEs, complementing Sitkowski et al. (2011) who showed that storm size growth can also happen via multiple ERCs. The dynamics of this long-lived CE phenomenon is important for obtaining a complete understanding of intensity and structural changes of TCs. Future work should be focused on understanding the dynamics of long-lived CEs using idealized and real numerical modeling experiments.

Acknowledgments. This research is sponsored by National Science Council, Taiwan, under Grants NSC100-2811-M-002-149, NSC-100-2111-M-002-004-MY3, NSC-100-2628-M-002-019, and by the U.S. Office of Naval Research NICOP Grant N62909-11-1-7096.

\section{REFERENCES}

Alishouse, J. C., S. A. Snyder, J. Vongsathorn, and R. R. Ferraro, 1990: Determination of oceanic total precipitable water from the SSM/I. IEEE Trans. Geosci. Remote Sens., 28, 811-815, doi:10.1109/36.58967.

Black, M. L., and H. E. Willoughby, 1992: The concentric eyewall cycle of Hurricane Gilbert. Mon. Wea. Rev., 120, 947-957, doi:10.1175/1520-0493(1992)120<0947:TCECOH>2.0.CO;2.

Hawkins, J. D., and M. Helveston, 2004: Tropical cyclone multiple eyewall characteristics. 26th Conf. on Hurricane and Tropical Meteorology, Miami, FL, Amer. Meteor. Soc., P1.7. [Available online at https://ams.confex.com/ams/26HURR/techprogram/ paper_76084.htm.] 
- , and - 2008: Tropical cyclone multiple eyewall characteristics. 28th Conf. on Hurricanes and Tropical Meteorology, Orlando, FL, Amer. Meteor. Soc., 14B.1. [Available online at https://ams.confex.com/ams/28Hurricanes/techprogram/paper 138300.htm.]

— , T. F. Lee, F. J. Turk, C. Sampson, J. Kent, and K. Richardson, 2001: Real-time Internet distribution of satellite products for tropical cyclone reconnaissance. Bull. Amer. Meteor. Soc., 82, 567-578, doi:10.1175/1520-0477(2001)082<0567: RIDOSP $>2.3 . \mathrm{CO} ; 2$.

- , M. Helveston, T. F. Lee, F. J. Turk, K. Richardson, C. Sampson, J. Kent, and R. Wade, 2006: Tropical cyclone multiple eyewall characteristics. 27th Conf. on Hurricane and Tropical Meteorology, Monterey, CA, Amer. Meteor. Soc., 6B.1. [Available online at http://ams.confex.com/ams/27Hurricanes/ techprogram/paper_108864.htm.]

Kummerow, C., W. Barnes, T. Kozu, J. Shiue, and J. Simpson, 1998: The Tropical Rainfall Measuring Mission (TRMM) sensor package. J. Atmos. Oceanic Technol., 15, 809-817, doi:10.1175/ 1520-0426(1998)015<0809:TTRMMT>2.0.CO;2.

Kuo, H.-C., L.-Y. Lin, C.-P. Chang, and R. T. Williams, 2004: The formation of concentric vorticity structures in typhoons. J. Atmos. Sci., 61, 2722-2734, doi:10.1175/JAS3286.1.

_- C.-P. Chang, Y.-T. Yang, and H.-J. Jiang, 2009: Western North Pacific typhoons with concentric eyewalls. Mon. Wea. Rev., 137, 3758-3770, doi:10.1175/2009MWR2850.1.

Maclay, K. S., M. DeMaria, and T. H. Vonder Haar, 2008: Tropical cyclone inner-core kinetic energy evolution. Mon. Wea. Rev., 136, 4882-4898, doi:10.1175/2008MWR2268.1.

Ortt, D., and S. S. Chen, 2008: Effect of environmental moisture on rainbands in Hurricane Rita and Katrina (2005). 28th Conf. on Hurricanes and Tropical Meteorology, Miami, FL, Amer. Meteor. Soc., 5C.5. [Available online at https://ams.confex. com/ams/28Hurricanes/techprogram/paper_138161.htm.]

Qiu, B., 1999: Seasonal eddy field modulation of the North Pacific Subtropical Countercurrent: TOPEX/Poseidon observations and theory. J. Phys. Oceanogr., 29, 2471-2486, doi:10.1175/ 1520-0485(1999)029<2471:SEFMOT $>2.0 . \mathrm{CO} ; 2$.

Qiu, X., Z.-M. Tan, and Q. Xiao, 2010: The roles of vortex Rossby waves in hurricane secondary eyewall formation. Mon. Wea. Rev., 138, 2092-2109, doi:10.1175/2010MWR3161.1.

Sitkowski, M., J. P. Kossin, and C. M. Rozoff, 2011: Intensity and structure changes during hurricane eyewall replacement cycles. Mon. Wea. Rev., 139, 3829-3847, doi:10.1175/ MWR-D-11-00034.1.

Terwey, W. D., and M. T. Montgomery, 2008: Secondary eyewall formation in two idealized, full-physics modeled hurricanes. J. Geophys. Res., 113, D12112, doi:10.1029/2007JD008897.

Willoughby, H. E., and P. G. Black, 1996: Hurricane Andrew in Florida: Dynamics of a disaster. Bull. Amer. Meteor. Soc., 77, 543-549, doi:10.1175/1520-0477(1996)077<0543: $\mathrm{HAIFDO}>2.0 . \mathrm{CO} ; 2$.

— J. A. Clos, and M. G. Shoreibah, 1982: Concentric eye walls, secondary wind maxima, and the evolution of the hurricane vortex. J. Atmos. Sci., 39, 395-411, doi:10.1175/ 1520-0469(1982)039<0395:CEWSWM > 2.0.CO;2.

Wimmers, A. J., and C. S. Velden, 2011: Seamless advective blending of total precipitable water retrievals from polarorbiting satellites. J. Appl. Meteor. Climatol., 50, 1024-1036, doi:10.1175/2010JAMC2589.1.

Yang, Y.-T., H.-C. Kuo, E. A. Hendricks, and M. S. Peng, 2013: Structural and intensity changes of concentric eyewall typhoons in the western North Pacific basin. Mon. Wea. Rev., 141, 26322648, doi:10.1175/MWR-D-12-00251.1.

Zhang, Q.-H., S.-J. Chen, Y.-H. Kuo, K.-H. Lau, and R. A. Anthes, 2005: Numerical study of a typhoon with a large eye: Model simulation and verification. Mon. Wea. Rev., 133, 725-742, doi:10.1175/MWR2867.1.

Zhou, X., and B. Wang, 2009: From concentric eyewall to annular hurricane: A numerical study with the cloud-resolving WRF model. Geophys. Res. Lett., 36, L03802, doi:10.1029/ 2008GL036141. 